\title{
Interactive comment on "Modeling the impact of heterogeneous reactions of chlorine on summertime nitrate formation in Beijing, China" by Xionghui Qiu et al.
}

Xionghui Qiu et al.

qiuxh1986@163.com

Received and published: 14 April 2019

The comment was uploaded in the form of a supplement:

https://www.atmos-chem-phys-discuss.net/acp-2018-1270/acp-2018-1270-AC1-

supplement.pdf

Interactive comment on Atmos. Chem. Phys. Discuss., https://doi.org/10.5194/acp-2018-1270, 2018. 